\title{
ADAKAH HUTAN MANGROVE DI MASA DEPAN?
}

\author{
Aswar Rustam*, Syarif Hidayat Amrullah, Dirhamzah \\ Jurusan Biologi UIN Alauddin Makassar \\ *E-mail: aswar.rustam@uin-alauddin.ac.id
}

\begin{abstract}
Abstrak: Ekosistem hutan mangrove sejatinya memiliki potensial produksi yang sangat tinggi. Tidak diragukan lagi bahwa hutan mangrove mampu meredam kecepatan dan kekuatan gelombang. Ekosistem mangrove sangat rentang jika dihadapkan dengan perkembangan kota. Kenyataannya, proyek tersebut terkadang bersinggungan langsung dengan masyarakat. Masyarakat yang merasakan dampak yang paling besar adalah nelayan. Pemerintah terkadang secara paksa memperoleh hak atas wilayah pesisir dari masyarakat, kemudian membuka hutan mangrove, lalu menimbunnya dengan pasir untuk kepentingan pembangunan proyek. Penelitian terbaru mengenai kematian spesies mangrove menjelaskan bahwa spesies yang tergolong dalam mangrove mungkin terpengaruh oleh perubahan iklim dunia. Rehabilitasi merupakan strategi kunci untuk mengimbangi deforestasi mangrove yang terus berlanjut di seluruh wilayah tropis.
\end{abstract}

Kata kunci: ekosistem mangrove, perubahan iklim, rehabilitasi, reklamasi

\section{PENDAHULUAN}

$\mathrm{E}$ kosistem hutan mangrove sejatinya memiliki potensial produksi yang sangat tinggi (Neogi et al., 2017). Tidak diragukan lagi bahwa hutan mangrove mampu meredam kecepatan dan kekuatan gelombang (Rustam et al., 2017), sehingga ekosistem hutan mangrove sangat ideal dijadikan sebagai tempat perlindungan terhadap tsunami, gelombang badai, erosi dan bencana pantai lainnya (Ghazali et al., 2016). Ekosistem hutan mangrove juga sebagai penyerap karbon yang sangat handal (Ragavan et al., 2019). Terbukti bahwa ekosistem hutan mangrove diperkirakan mampu menyimpan karbon sebesar $46 \%$ dalam bentuk biomassa di atas tanah yang mengendap (Jaikishun et al., 2017; Windarni et al., 2018). Selain itu, di India, ekosistem mangrove menjadi habitat dari 4000 spesies tumbuhan dan hewan (DasGupta \& Shaw, 2017).

Ekosistem hutan mangrove sangat rentang jika dihadapkan dengan perkembangan kota (Rahadian et al., 2019). Terjadinya aktivitas reklamasi di daerah pesisir menjadi sebuah tren terbaru dalam mengembangkan wilayah perkotaan. Pengembangan tersebut dimaksudkan agar tejadi peningkatan pendapatan daerah dan juga adanya program pemerintah mengenai konservasi pesisir dan laut. Selain itu, reklamasi juga sekaligus menjadi ajang investasi dengan membangun hunian-hunian di tepi pantai (Hadi et al., 2018). Kenyataannya, proyek tersebut terkadang bersinggungan langsung dengan masyarakat di daerah pesisir. Masyarakat yang merasakan dampak yang paling besar adalah nelayan (Said, 2019). Penutupan atau pembatasan akses dilakukan demi menuntaskan kegiatan ini menyebabkan penurunan pendapatan warga sekitar proyek selama dan setelah pengerjaan proyek reklamasi (Anwar dan Aswandi, 2019). 


\section{REKLAMASI}

Ekosistem mangrove tengah menghadapi masalah yang serius. Kondisi ini disebabkan karena adanya berbagai kegiatan perluasan lahan, seperti pembangunan perkotaan (Tay et al., 2018). Kerusakan ekosistem hutan mangrove semakin parah di negara berkembang akibat bencana alam dan proses antropogenik yang meliputi kurangnya partisipasi dan kesadaran masyarakat tentang pentingnya ekosistem ini. Reklamasi lanskap pesisir dimaksudkan untuk memperluas wilayah perkotaan, pembangunan infrastruktur seperti jalan, pembangunan lahan pemukiman, eksplorasi minyak mentah dan penambangan pasir (Chee et al., 2017; Numbere, 2020). Pemerintah terkadang secara paksa memperoleh hak atas wilayah pesisir dari masyarakat, kemudian membuka hutan mangrove, lalu menimbunnya dengan pasir untuk kepentingan pembangunan proyek (Estoque et al., 2018). Kondisi ini juga diperparah dengan meningkatnya populasi masyarakat, sehingga dilakukannya reklamasi guna menciptakan ruang huni untuk menampung lebih banyak orang. Namun, banyak kegiatan reklamasi tidak berpusat pada pembangunan, namun lebih cenderung ke bisnis (Numbere, 2020).

Kasus reklamasi yang terjadi di Delta (Gambar 1) disebabkan karena adanya peningkatan populasi sehingga terjadinya migrasi penduduk menuju lokasi pesisir. Penyebab reklamasi lahan di Delta Niger dikelompokkan menjadi dua, yaitu penyebab langsung dan penyebab tidak langsung. Penyebab langsungnya meliputi perluasan lahan, kegiatan konstruksi, pembebasan lahan dan suksesi (kegiatan pembentukan lahan mangrove). Penyebab tidak langsung meliputi penambangan pasir, kegiatan eksplorasi, perluasan aliran/kanalisasi, pembatasan gangguan dan pertanian (40-50\% permukaan lahan diubah menjadi pertanian dan sistem perkotaan) (Numbere, 2020).

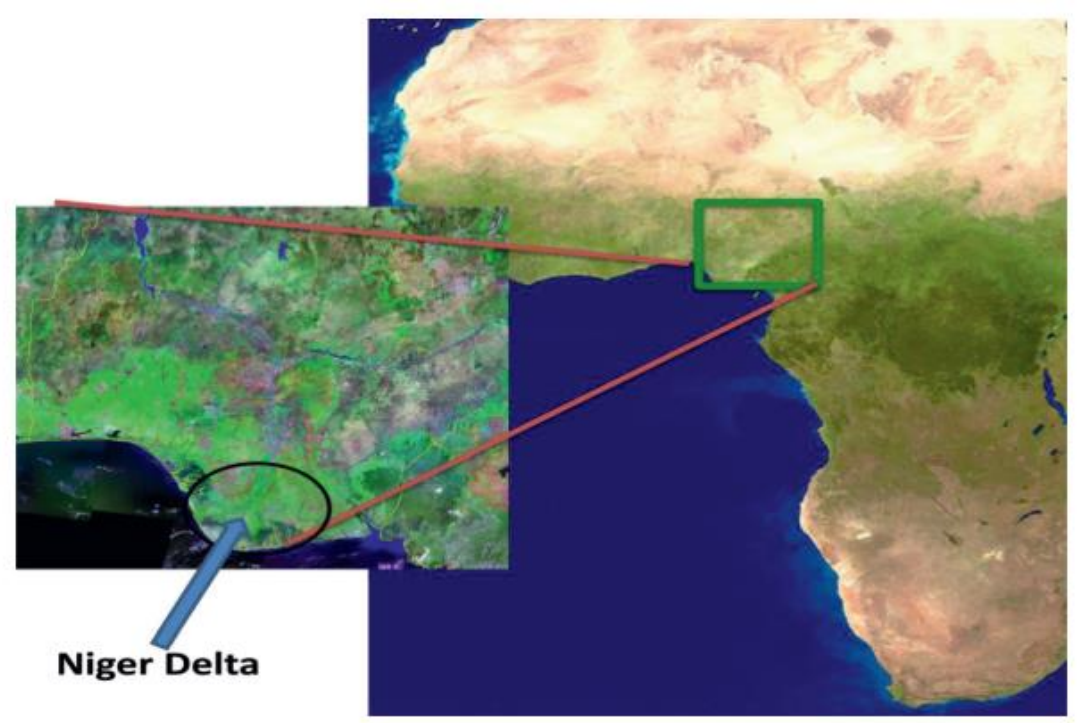

Gambar 1. Peta Delta Nigeria (lingkaran hitam) yang merupakan wilayah mangrove terbesar di Afrika (Numbere, 2020)

Kondisi lain terjadi pada ekosistem mangrove di Pulau Ayer, Singapura. Rekonstruksi pulau Ayer menggunakan peta topografi tahun 1969, 1983, 1993, dan 2002 menunjukkan bahwa sebelumnya terdapat ekosistem terumbu karang dan hutan mangrove (Gambar 2). Selama kegiatan reklamasi, kedua ekosistem tersebut dihilangkan. Hasil analisis menggunakan ArcMap, luas terumbu karang di pulau Ayer hingga 10,07 
$\mathrm{km}^{2}$ dan hutan mangrove seluas $5,25 \mathrm{~km}^{2}$ pada tahun 1969(

Tabel 1). Meskipun proyek reklamasi resmi untuk menggabungkan pulau Ayer menjadi pulau Jurong dimulai pada tahun 1995, kawasan terumbu karang dan hutan mangrove sudah mengalami penurunan sebelumnya (Tay et al., 2018). Laju kerusakan hutan mangrove lebih cepat disebabkan oleh pembangunan pabrik di pulau Ayer.
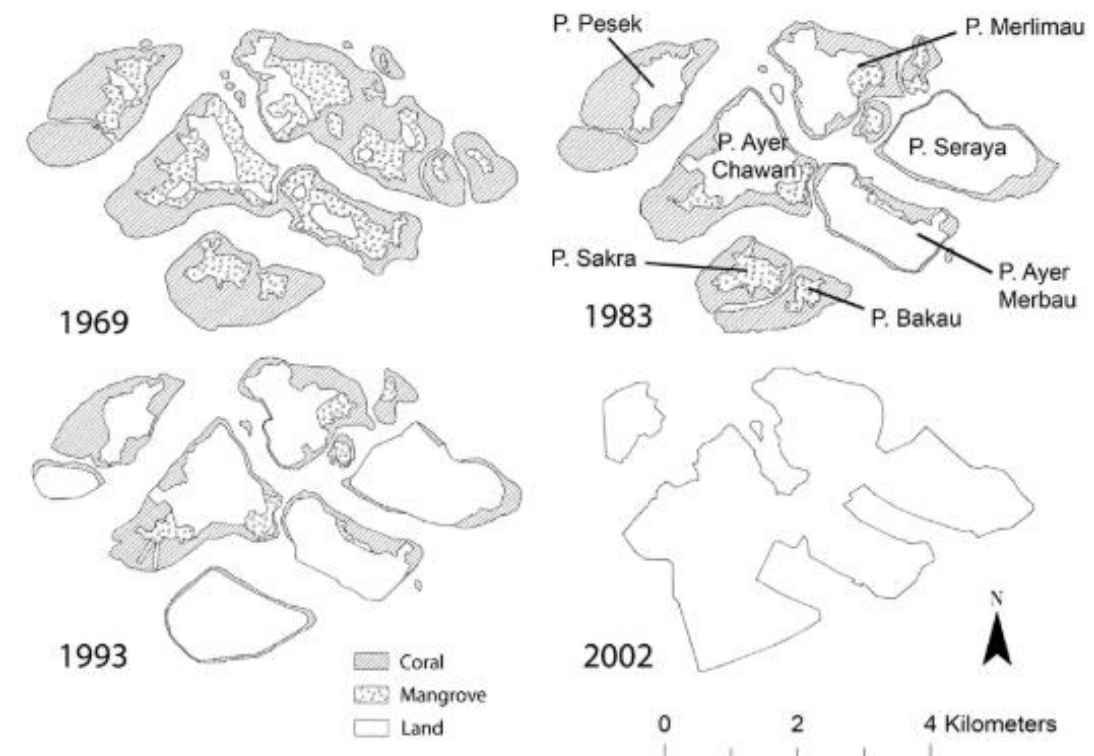

Gambar 2 Peta yang merepresentasikan keberadaan ekosistem terumbu karang dan hutan mangrove di pulau Ayer sejak tahun 1969-2002 (Tay et al., 2018)

Tabel 1. Data area ekosistem terumbu karang dan hutan mangrove di pulau Ayer tahun 19692020

\begin{tabular}{ccccccc}
\hline Tahun & $\begin{array}{c}\text { Tutupan } \\
\text { Terumbu } \\
\text { Karang } \\
\left(\mathrm{km}^{2}\right)\end{array}$ & $\begin{array}{c}\text { Tingkat } \\
\text { Kehilangan } \\
\text { Tutupan } \\
\text { Terumbu } \\
\text { Karang } \\
\left(\mathrm{km}^{2} / \text { tahun }\right)\end{array}$ & $\begin{array}{c}\text { Tutupan } \\
\left(\mathrm{km}^{2}\right)\end{array}$ & $\begin{array}{c}\text { Tingkat } \\
\text { Kehilangan } \\
\text { Tutupan } \\
\text { Mangrove } \\
\left(\mathrm{km}^{2} / \text { tahun }\right)\end{array}$ & $\begin{array}{c}\text { Tutupan } \\
\left(\mathrm{km}^{2}\right)\end{array}$ & $\begin{array}{c}\text { Tingkat } \\
\text { Perolehan } \\
\text { Tutupan } \\
\text { Lahan } \\
\left(\mathrm{km}^{2} / \text { tahun }\right)\end{array}$ \\
\hline 1969 & 10.078 & - & 5.250 & - & 1.863 & - \\
\hline 1983 & 7.108 & 0.212 & 1.487 & 0.268 & 7.472 & 0.400 \\
\hline 1993 & 4.594 & 0.251 & 0.796 & 0.069 & 9.902 & 0.243 \\
\hline 2002 & - & 0.510 & - & 0.088 & 12.348 & 0.382 \\
\hline Sumber: Tay et al., 2018 & & & & &
\end{tabular}

Kemungkinan besar hutan mangrove ditebang dan direklamasi untuk mengakomodasi perluasan pabrik dan mengakibatkan penurunan tutupan hutan bakau dari tahun 1969-1983, dan peningkatan paralel tutupan lahan pada periode yang sama. Terlepas dari tren negatif dari perubahan iklim terhadap ekosistem mangrove, munculnya kegiatan pertambakan juga memicu turunnya angka kehadiran mangrove di berbagai wilayah dunia (de Lacerda et al., 2019).

\section{PERUBAHAN IKLIM}

Ekosistem hutan mangrove dikenal mampu menyediakan layanan jasa yang penting terhadap daratan dan lautan sekaligus. Penelitian terbaru mengenai kematian spesies 
mangrove menjelaskan bahwa spesies yang tergolong dalam mangrove mungkin terpengaruh oleh perubahan iklim dunia (Sippo et al., 2018). Kehilangan mangrove sebagai akibat dari perubahan iklim terutama disebabkan oleh peningkatan laju kenaikan permukaan laut, kejadian air yang tinggi, badai, dan curah hujan serta pola sirkulasi laut yang berubah, kesehatan ekosistem yang terkait secara fungsi, dan kegiatan sosial ekonomi (Feller et al., 2017). Selain itu, respon mangrove terhadap pengingkatan frekuensi dan/atau intensitas badai, pengingkatan suhu, dan kekeringan juga menunjukkan bahwa mangrove dipengaruhi oleh perubahan iklim (Jennerjahn et al., 2017). Faktor-faktor tersebut mempengaruhi ketahanan hutan mangrove. Kenaikan permukaan laut akan sangat mempengaruhi meskipun dampaknya cenderung lebih bervariasi (Ward et al., 2016).

Mangrove tidak seperti tumbuhan pesisir lainnya tidak mengalami perluasan wilayah meskipun suhu permukaan meningkat (Hickey et al., 2017). Alongi (2015) memprediksikan bahwa dampak perubahan iklim paling parah akan dirasakan oleh mangrove di sepanjang pantai yang gersang karena salinitas meningkat, suplai air tawar menurun, dan ambang batas suhu kritis tercapai. Meskipun perubahan iklim secara umum dianggap sebagai ancaman bagi mangrove di daerah tropis dan sub tropis, interaksi dengan proses perubahan iklim juga dapat menyebabkan peningkatan kawasan mangrove melalui setidaknya dua mekanisme (Feller et al., 2017). Pertama, mangrove dapat merespons kenaikan permukaan laut setidaknya dalam tiga cara yaitu dengan menenggelamkan, dengan membangun secara vertikal, dan jika bangunan vertikal memadai dan koridor ada, dengan bermigrasi ke lahan basah yang berdekatan (Krauss, Mckee, Lovelock, et al., 2014). Kedua, semakin banyak bukti yang menunjukkan bahwa perubahan iklim memengaruhi rentang lintang hutan mangrove, termasuk penelitian terbaru tentang perluasan mangrove di dekat batas pesisir lima benua (Saintilan et al., 2014).

Tabel 2. Dampak langsung dan tidak langsung perubahan iklim serta dampak langsung kegiatan manusia terhadap ekosistem hutan mangrove

\begin{tabular}{lll}
\hline $\begin{array}{c}\text { Dampak Langsung } \\
\text { Perubahan Iklim }\end{array}$ & $\begin{array}{c}\text { Dampak Tidak Langsung Perubahan } \\
\text { Iklim }\end{array}$ & $\begin{array}{c}\text { Dampak Langusng dari } \\
\text { Manusia }\end{array}$ \\
\hline - Kenaikan & - Perubahan sikulasi samudera & - Pembukaan lahan \\
permukaan laut & sehingga berdampak pada ombak & - Perubahan jalur air dan \\
- Memanasnya & mangrove & ombak \\
permukaan air & mengan geospasial & Perubahan jalur \\
- Memanasnya suhu & - Perubahan salinitas & masuknya air tawar \\
udara & mempengaruhi pertukaran & - Perubahan sedimen \\
- Perubahan & ombak & sungai yang tertahan \\
atmosfer & - Permukaan air menjadi asam & - Polusi \\
- Perubahan & - Perubahan aliran air tawar & - Eksploitasi hutan dan \\
komposisi gas di & - Perubahan sedimen yang & perikanan \\
atmosfer $\left(\mathrm{CO}_{2}\right.$ & tertahan & Kegiatan pertambangan \\
lebih tinggi) & - Perubahan iklim yang ekstrim & minyak, petroleum, dan \\
& - Meningkatnya frekuensi dari & air \\
& iklim ekstrim & \\
& - Perubahan musim & \\
\hline
\end{tabular}

Terdapat efek langsung perubahan iklim yang berpotensi mengubah struktur, fungsi, dan ekosistem hutan mangrove. Namun, efek ini juga mengubah pengaturan fisik, 
kimia, biologi, dan geomorfologi lingkungan mangrove. Hal ini, pada gilirannya, secara tidak langsung dapat mengubah struktur, fungsi, dan ekosistem hutan mangrove melalui pertukaran yang berubah dengan ekosistem sekitarnya, termasuk efek dari berbagai penyebab stres perubahan iklim dan penyebab stres antropogenik dan alami lainnya pada sistem mangrove (Tabel 2). Ada juga mekanisme umpan balik potensial dari hasil perubahan iklim yang dapat mempengaruhi ketahanan dan ketahanan mangrove (Krauss, Mckee, \& Hester, 2014).

\section{REHABILITASI}

Rehabilitasi merupakan strategi kunci untuk mengimbangi deforestasi mangrove yang terus berlanjut di seluruh wilayah tropis. Upaya rehabilitasi ekosistem hutan mangrove selama beberapa tahun terakhir telah membuahkan hasil. Pemahaman masyarakat tentang pentingnya perlindungan ekosistem mangrove mengalami peningkatan (Feller et al., 2017). Namun, motivasi pendorong aksi rehabilitasi mangrove di perkotaan berbeda dengan daerah pedesaan. Perbedaan tersebut terkait dengan penggantian habitat atau pemanfaatan fungsi redaman gelombang untuk pertahanan asset pesisir perkotaan. Selain itu, keterbatasan penggunaan ruang dan habitat baru kurang cocok untuk pembentukan ekosistem mangrove (Friess, 2017).

Rehabilitasi ekosistem hutan mangrove mampu meningkatkan unsur hara tanah. Unsur karbon, nitrogen, dan kalium meningkat secara signifikan di wilayah rehabilitasi. Kondisi ini kemudian mampu mempengaruhi kesehatan bibit mangrove (Bakrin Sofawi et al., 2017). Strategi rehabilitasi ekosistem mangrove yang dapat dilakukan diantaranya memanfaatkan sumber daya dalam reboisasi hutan, membuat sebuah hutan lindung ataupun hutan konservasi, mensosialisasikan pentingnya ekosistem hutan mangrove untuk lautan dan daratan sehingga berdampak positif terhadap kesejahteraan masyarakat (Utomo et al., 2017). Selain itu, pola tanam juga harus diperhatikan (Bakrin Sofawi et al., 2017). Penelitian Rustam et al. (2017) menunjukkan bahwa kecepatan rata-rata, tekanan dinamis, dan koefisien ombak berbeda untuk setiap pola tanam. Variabel kecepatan terendah menggunakan pola alami, sebesar $1,10 \mathrm{~m} / \mathrm{s}$, sedangkan kecepatan tertinggi berada pada pola sejajar, sebesar $1,25 \mathrm{~m} / \mathrm{s}$. Variabel tekanan dinamis terendah pada pola alami, sebesar 636,71 Pa, sedangkan yang tertinggi pada pola sejajar, sebesar 792,01 Pa. Variabel koefisien seret tertinggi pada pola alami, sebesar 0,14 (RMSE: 6x104), sedangkan yang terendah pada pola sejajar, sebesar 0,03 (RMSE: 2x10-4). Sebagai catatan bahwa variable koefisien seret berbanding terbalik dengan variable kecepatan rata-rata dan tekanan dinamis ombak. Variabel kecepatan rata-rata ombak pada pola silang, sejajar, dan alami akan berubah. Kondisi ini terkait dengan kerapatan vegetasi yang ditanam. Sebaliknya, variabel koefisien seret, pada kondisi vegetasi yang semakin padat, maka variabel tersebut juga akan semakin tinggi. Ketika vegetasi yang akan ditanam semakin jarang, maka variabel koefisien seret akan berkurang.

\section{KESIMPULAN}

Fungi ekosistem hutan mangrove sangat penting. Ekosistem hutan mangrove, melalui system perakaran yang unik, mampu meredam kecepatan dan kekuatan gelombang, sehingga sebagai tempat perlindungan flora dan fauna pesisir. Ekosistem ini juga dijadikan sebagai pelindung tsunami, gelombang badai, erosi dan bencana pantai lainnya. Namun, ekosistem ini tengah menghadapi masalah yang serius. Adanya berbagai 
kegiatan perluasan lahan, seperti pembangunan perkotaan dan pertambakan membuat semakin berkurangnya tutupan lahan mangrove. Selain itu, penelitian terbaru menjelaskan bahwa spesies yang tergolong dalam mangrove mungkin terpengaruh oleh perubahan iklim dunia, sehingga diperlukannya upaya rehabilitasi sebagai strategi kunci untuk mengimbangi deforestasi mangrove yang terus berlanjut di seluruh wilayah tropis.

\section{DAFTAR PUSTAKA}

Alongi, D. M. (2015). The Impact of Climate Change on Mangrove Forests. Current Climate Change Reports, 1(1), 30-39. https://doi.org/10.1007/s40641-015-0002-x.

Anwar, A. F., \& Aswandi, K. (2019). Silang sengkarut pembangunan berkelanjutan perkotaan dalam pusaran kapital (Studi kasus: Megaproyek reklamasi CPI Makassar). EcceS (Economics, Social, and Development Studies), 6(1), 1-17. https://doi.org/10.24252/ecc.v6i1.9540.

Bakrin Sofawi, A., Rozainah, M. Z., Normaniza, O., \& Roslan, H. (2017). Mangrove rehabilitation on Carey Island, Malaysia: an evaluation of replanting techniques and sediment properties. Marine Biology Research, 13(4), 390-401. https://doi.org/10.1080/17451000.2016.1267365.

Chee, S. Y., Othman, A. G., Sim, Y. K., Mat Adam, A. N., \& Firth, L. B. (2017). Land reclamation and artificial islands: Walking the tightrope between development and conservation. Global Ecology and Conservation, 12, 80-95. https://doi.org/10.1016/j.gecco.2017.08.005.

DasGupta, R., \& Shaw, R. (2017). Mangroves in India and Climate Change: An Overview. In Participatory Mangrove Management in a Changing Climate, 1, 336. https://doi.org/10.1007/978-4-431-56481-2.

de Lacerda, L. D., Borges, R., \& Ferreira, A. C. (2019). Neotropical mangroves: Conservation and sustainable use in a scenario of global climate change. Aquatic Conservation: Marine and Freshwater Ecosystems, 29(8), 1347-1364. https://doi.org/10.1002/aqc.3119.

Estoque, R. C., Myint, S. W., Wang, C., Ishtiaque, A., Aung, T. T., Emerton, L., Ooba, M., Hijioka, Y., Mon, M. S., Wang, Z., \& Fan, C. (2018). Assessing environmental impacts and change in Myanmar's mangrove ecosystem service value due to deforestation (2000-2014). Global Change Biology, 24(11), 5391-5410. https://doi.org/10.1111/gcb.14409.

Feller, I. C., Friess, D. A., Krauss, K. W., \& Lewis, R. R. (2017). The state of the world's mangroves in the 21st century under climate change. Hydrobiologia, 803(1), 1-12. https://doi.org/10.1007/s10750017-3331-z.

Friess, D. A. (2017). Mangrove rehabilitation along urban coastlines: A Singapore case study. Regional Studies in Marine Science, 16, 279-289. https://doi.org/10.1016/j.rsma.2017.09.013.

Ghazali, N., Zainuddin, K., Zainal, M. Z., Dali, H. M., Samad, A. M., \& Mahmud, M. R. (2016). The potential of mangrove forest as a bioshield in Malaysia. 2016 IEEE 12th International Colloquium on Signal Processing and Its Applications, CSPA, March, 322-327. https://doi.org/10.1109/CSPA.2016.7515854.

Hadi, S., Syarifudin, T. Y., \& Alfath, T. P. (2018). Perlindungan Hak Asasi Manusia, Pengelolaan Wilayah Pesisir dan Pulau-Pulau Kecil. Lex Scientia Law Review, 2(2), 215-226.

Hickey, S. M., Phinn, S. R., Callow, N. J., Van Niel, K. P., Hansen, J. E., \& Duarte, C. M. (2017). Is Climate Change Shifting the Poleward Limit of Mangroves? Estuaries and Coasts, 40(5), 1215-1226. https://doi.org/10.1007/s12237-017-0211-8.

Jaikishun, S., Ansari, A. A., Dasilva, P., \& Hosen, A. (2017). Carbon storage potential of mangrove forest in Guyana. Bonorowo Wetlands, 7(1), 43-54. https://doi.org/10.13057/bonorowo/w070109.

Jennerjahn, T. C., Gilman, E., Krauss, K. W., Lacerda, L. D., Nordhaus, I., \& Wolanski, E. (2017). Mangrove ecosystems under climate change. In Mangrove Ecosystems: A Global Biogeographic Perspective: Structure, Function, and Services, 211-244. https://doi.org/10.1007/978-3-319-622064_7.

Krauss, K. W., Mckee, K. L., \& Hester, M. W. (2014). Water use characteristics of black mangrove (Avicennia germinans) communities along an ecotone with marsh at a northern geographical limit. 
Ecohydrology, 7(2), 354-365. https://doi.org/10.1002/eco.1353.

Krauss, K. W., Mckee, K. L., Lovelock, C. E., Cahoon, D. R., Saintilan, N., Reef, R., \& Chen, L. (2014). How mangrove forests adjust to rising sea level. New Phytologist, 202(1), 19-34. https://doi.org/10.1111/nph.12605.

Neogi, S. B., Dey, M., Kabir, S. L., Masum, S. J. H., Kopprio, G., Yamasaki, S., \& Lara, R. (2017). Sundarban mangroves: diversity, ecosystem services and climate change impacts. Asian Journal of Medical and Biological Research, 2(4), 488-507. https://doi.org/10.3329/ajmbr.v2i4.30988.

Numbere, A. O. (2020). The Impact of Landscape Reclamation on Mangrove Forest and Coastal Areas in the Niger Delta, Nigeria. In Landscape Reclamation - Rising From What's Left, 1-18. https://doi.org/10.5772/intechopen.82053.

Ragavan, P., Sivakumar, K., Jayaraj, R. S. C., Mohan, P. M., \& Rana, T. S. (2019). Carbon storage potential of mangroves - are we missing the boat? Current Science, 116(6), 889-891. https://doi.org/10.18520/cs/v116/i12/2071-2071.

Rahadian, A., Leilan, F., Arafat, I. N., \& Lestari, T. A. (2019). Ecosystem mangrove management in urban area: Case study mangrove Kali Adem Jakarta Indonesia. IOP Conference Series: Earth and Environmental Science, 399, 1-9. https://doi.org/10.1088/1755-1315/399/1/012008.

Rustam, A., Qayim, I., \& Erizal. (2017). Kerapatan vegetasi, model arsitektur akar, serta simulasi hidrodinamika Rhizophora apculata Bl. di Teluk Bone, Sulawesi Selatan. Media Konservasi, 22(1), 19-25. https://doi.org/10.29243/medkon.22.1.19-25.

Said, M. (2019). Reklamasi dan dampaknya terhadap wilayah pesisir pantai Toboko, Kota Ternate. Dintek, 12(2), 83-91.

Saintilan, N., Wilson, N. C., Rogers, K., Rajkaran, A., \& Krauss, K. W. (2014). Mangrove expansion and salt marsh decline at mangrove poleward limits. Global Change Biology, 20(1), 147-157. https://doi.org/10.1111/gcb.12341.

Sippo, J. Z., Lovelock, C. E., Santos, I. R., Sanders, C. J., \& Maher, D. T. (2018). Mangrove mortality in a changing climate: An overview. Estuarine, Coastal and Shelf Science, 215, 241-249. https://doi.org/10.1016/j.ecss.2018.10.011.

Tay, J. Y. L., Wong, S. K. M., Chou, L. M., \& Todd, P. A. (2018). Land reclamation and the consequent loss of marine habitats around the Ayer Islands, Singapore. Nature In Singapore, 11, 1-5.

Utomo, B., Budiastuty, S., \& Muryani, C. (2017). Strategi pengelolaan hutan mangrove di Desa Tanggul Tlare Kecamatan Kedung Kabupaten Jepara. Jurnal Ilmu Lingkungan, 15(2), 117-123. https://doi.org/10.14710/jil.15.2.117-123.

Ward, R. D., Friess, D. A., Day, R. H., \& Mackenzie, R. A. (2016). Impacts of climate change on mangrove ecosystems: a region by region overview. Ecosystem Health and Sustainability, 2(4). https://doi.org/10.1002/ehs2.1211.

Windarni, C., Setiawan, A., \& Rusita, R. (2018). Carbon Stock Estimation of Mangrove Forest in Village Margasari Sub-District Labuhan Maringgai District East Lampung. Jurnal Sylva Lestari, 6(1), 66. https://doi.org/10.23960/js11667-75. 